\title{
Texture Profile Characteristics In Horse Meat
}

\author{
Emanuiel C. DIACONU*, Roxana LAZĂR, Nicoleta GĂINĂ (DIACONU), Marius M. CIOBANU, \\ Paul C. BOIŞTEANU
}

Department of Fundamental Sciences in Animal Husbandry, University of Agricultural Sciences and Veterinary Medicine Iaşi, Romania

*Corresponding author, email: diaconuemi@yahoo.com

Bulletin UASVM Animal Science and Biotechnologies 71(2) / 2014,

Print ISSN 1843-5262; Electronic ISSN 1843-536X

DOI: $10.15835 /$ buasvmcn-asb:10479

\begin{abstract}
Meat had and has an essential role in human nutrition and human development. Due to perceptions of heart disease caused by eating red meat, consumers seeking alternatives to achieve the necessary protein, also looking the piece of meat that owns most of the organoleptic properties: tenderness, juiciness, etc.

A significant influence on meat texture has the physiological function of the muscle in relation to its anatomical position, age at slaughter, the type of nutrition offered to horses.

The aim of this paper is to analyze different tissues muscle from horses slaughtered in our country, in terms of textural characteristics involved: hardness, cohesiveness, adhesiveness, gumminess, elasticity, chewiness.

Textural profile (TPA) of these samples was performed using dynamometer Llyod Plus LPF and expression of results were made possible by embedded software NEXYGEN Ondio.

Most parameters that describe the texture of horse meat showed insignificant differences between the 4 groups of muscles, M. Longissimus dorsi recorded their highest values. Significant differences were obtained in

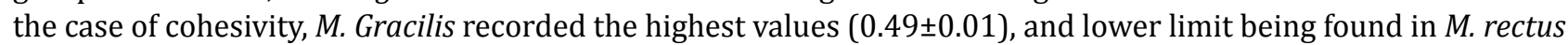
abdominis with an average of $0.42 \pm 0.02$.

The results obtained for all the parameters that describe textural profile help us to appreciate the horse meat quality, assessment which may lead to interpreting palatability of this kind of meat. Also, by determination of these physical parameters we assess the conditions that the meat is subjected to when the mastication take place.
\end{abstract}

Keywords: horses, palatability, texture profile

\section{INTRODUCTION}

Today consumers are more aware of what they eat, their health existing demand just on quality food products. Thus, they prefer meat with less fat (minimum fat level to provide needed meat juiciness and flavor) and quality consistent (Ward et al., 1995).

Consumption of horse meat has emerged as an alternative to meats considered "dietetic", due to the low fat, but having in composition essential elements for human organism. However, people are still apprehensive about the consumption of this type of meat, due to divergent opinion and illegal practices of slaughtering that exist, due to lack of horse growth systems for the purpose of slaughter for human consumption. (Lorenzo et al., 2014)
Meat tenderness and texture can be influenced by a number of factors including those related to animal (physical activity performed, pre-slaughter treatments) and those related to environmental conditions and processing technology (operators practices during slaughter, processing method of meat that result after slaughter).

The rheological behavior of the meat, including textural characteristics can be studied by several mechanical methods (compression, torsion, tension and shear). Currently the most commonly instrumental method used is WarnerBratzler shear force and textural profile analysis (TPA) -compression method (Bruna et al., 2000; Visessanguan et al., 2004).

Texture profile analysis (TPA) is the most popular compression method. TPA has been 
implemented to General Foods Texturometer (Szczęśniak et al., 1963), and this method involves compressing a sample at least twice, using a lower plate cylinder side in order to quantify the mechanical parameters of the curves generated by the force-distortion (Szczęśniak, 2002).

\section{MATERIALS AND METHODS}

The research was conducted on four types of muscle tissue derived from slaughtered horses from Botosani: Longissimus dorsi muscle, Gracilis muscle, Infraspinatus muscle, Rectus abdominis muscle.

In order to achieve the texture profile, meat samples were previous subjected to a heat treatment on bain for 45 minutes at $75^{\circ} \mathrm{C}$ in polyethylene bags, and then allowed to cool for about 4 hours.

In performing of the mechanical determination was used LFP Lloyd plus dynamometer, meat samples being in the form of cylinders with $\phi$ and $\mathrm{H}$ of $20 \mathrm{~mm}$. In order to obtain the results we used a pressure cylinder surfaced with $\varphi=45$ $\mathrm{m}$. Cutting the cylindrically shaped meat samples was performed at room temperature by pressing the sample with a cylinder parallel to the muscle fibers. Determination itself involved carrying out a double compression with a intermediate break between them of 5 seconds at $10 \mathrm{~mm} / \mathrm{min}$. speed, and a final distortion of $80 \%$ of the original height of the meat sample tested.

Expression of results quantities was performed using software NEXYGEN Ondio Integrated to LFP Lloyd plus dynamometer, that also allowed direct recording and calculating the values of each parameter descriptive textural (hardness, cohesiveness, adhesiveness, gumminess, elasticity, chewiness).

Taking the study on 5 samples for each muscle was necessary statistical calculation performed using Microsoft Excel.

\section{RESULTS AND DISCUSSION}

Description of meat textural profile of analyzed samples, by region muscle and physiological activity of the animal's life was made through 6 parameters resulting from mechanical tests, that are designed to simulate the conditions to which it is exposed when the chewing meat take place.

Textural properties of meat depend on other characteristics, including water holding capacity
(WHC) and fat content that is essential for chewability.

Regarding to meat hardness, an increased amount of fat can dilute significantly meat proteins, reducing the total density, which together with connective tissue fats reduces the force required to cut the meat.

Research on the hardness of the samples coming from the four muscle tissues of horses showed mean values between 17.76 \pm 5.46 and $37.71 \pm 5.09 \mathrm{~N}$, the minimum being recorded by Rectus Abdominis $M$. $(17.76 \pm 5.46 \mathrm{~N})$ and highs being recorded at Longissimus Dorsi $M$. (37.71 \pm 5.09 N). (Tab. 1)

Davey and Gilbert (1974b) mentioned in their paper that by boiling temperatures of 40 to $50^{\circ} \mathrm{C}$, the meat becomes more harshest, followed by a decrease in hardness when the temperature rises to $50 \div 60^{\circ} \mathrm{C}$.

Also, the increased hardness of the Longissimus dorsi $M$. may be due to the number and size of muscle fibers, thus increasing once with the physical activity performed during their lifetime.

In terms of texture feature represented by cohesiveness, the minima were recorded in Rectus abdominis $M$., with an average of $0.42 \pm 0.025$, and the calculated maximum being responsible for muscle Gracilis muscle $(0.49 \pm 0.01)$.

Similar values found for this parameter, for the muscle tissue of horses, were found in researches by Franco and Lorenzo (2014), which are ranging between 0.52 and 0.57 .

Comparing the averages for adhesion tests, there were no significant differences between values, ranging from -0.00012 to $0.0001 \mathrm{~J}$.

For gumminess parameter, the high average was recorded in Longissimus dorsi M., but Gracillis $M$. reached a maximum of $27.48 \mathrm{~N}$.

Measuring physical elasticity, the Rectus Abdominis M. showed the lowest mean value of $0.37 \pm 0.03$, and through the Longissimus dorsi $M$. and Infraspinatus $M$. was noted an increase in value, reaching an average of $0.46 \pm 0.02$.

Chewiness is facilitated by the structure of the meat, so marbled meat is perceived as juicy one, intramuscular fat stimulating the salivation process. A greater force was required to Longissimus dorsi $M$. calculated mean registering values of $8.6 \pm 1.5 \mathrm{~N}$. At the opposite pole was situated the Rectus Abdominis M., with a mean of $3.09 \pm 1.12 \mathrm{~N}$. 
Tab. 1. Descriptive parameters of muscle tissue texture from horsesL.D = Longissimus Dorsi; Grac.= M. Gracilis; I = M. Infraspinatus; R. Abd. = M. Rectus Abdominis

\begin{tabular}{|c|c|c|c|c|c|c|}
\hline \multirow{2}{*}{\multicolumn{2}{|c|}{ Specification }} & \multicolumn{4}{|c|}{ Statistical indicators calculated } & \multirow{2}{*}{$\begin{array}{l}\text { Significance of differ } \\
\text { ences between the } \\
\text { averages of lots } \\
\text { (FISHER Test) }\end{array}$} \\
\hline & & $\overline{\mathbf{x}} \pm s_{\overline{\mathbf{x}}}$ & V\% & Min. & Max. & \\
\hline \multirow{4}{*}{ 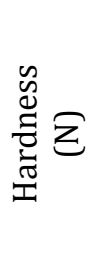 } & L.D & $37.71 \pm 5.09$ & 30.21 & 23.53 & 50.17 & \multirow{4}{*}{$\begin{aligned} \hat{\mathrm{F}}_{2.54}< & \mathrm{F}_{0.05 \%}(3.41) \\
& \rightarrow n . s\end{aligned}$} \\
\hline & Grac. & $28.19 \pm 5.93$ & 47.10 & 17.19 & 49.79 & \\
\hline & I. & $36.14 \pm 3.16$ & 17.52 & 27.4 & 42.56 & \\
\hline & R. Abd. & $17.76 \pm 5.46$ & 53.25 & 7.59 & 26.29 & \\
\hline \multirow{4}{*}{ 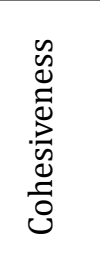 } & L.D & $0.47 \pm 0.005$ & 2.76 & 0.46 & 0.49 & \multirow{4}{*}{$\begin{array}{c}\hat{\mathrm{F}}_{3.59}>\mathrm{F}_{0.05 \%}(3.41) \\
\rightarrow *\end{array}$} \\
\hline & Grac. & $0.49 \pm 0.01$ & 8.78 & 0.45 & 0.55 & \\
\hline & I. & $0.48 \pm 0.009$ & 3.80 & 0.46 & 0.5 & \\
\hline & R. Abd. & $0.42 \pm 0.025$ & 10.38 & 0.37 & 0.45 & \\
\hline \multirow{4}{*}{ 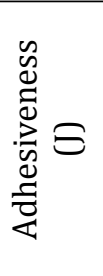 } & L.D & $-0.00012 \pm 0.0001$ & -352.34 & -0.0008 & 0.00021 & \multirow{4}{*}{$\begin{array}{c}\hat{\mathrm{F}}_{0.5}<\mathrm{F}_{0.05 \%}(3.41) \\
\rightarrow n . s\end{array}$} \\
\hline & Grac. & $0.0001 \pm 0.00004$ & 82.31 & 0.000015 & 0.00021 & \\
\hline & I. & $0.000045 \pm 0.0001$ & 488.72 & -0.00027 & 0.00023 & \\
\hline & R. Abd. & $-0.00004 \pm 0.00023$ & -1021.33 & -0.00051 & 0.00023 & \\
\hline \multirow{4}{*}{ 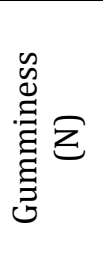 } & L.D & $17.97 \pm 2.45$ & 30.59 & 11.45 & 24.77 & \multirow{4}{*}{$\begin{array}{c}\hat{\mathrm{F}}_{2.18}<\mathrm{F}_{0.05 \%}(3.41) \\
\rightarrow n . s\end{array}$} \\
\hline & Grac. & $14.41 \pm 3.57$ & 55.37 & 7.94 & 27.48 & \\
\hline & I. & $17.55 \pm 1.73$ & 19.81 & 12.97 & 21.31 & \\
\hline & R. Abd. & $7.76 \pm 2.65$ & 59.19 & 2.81 & 11.89 & \\
\hline \multirow{4}{*}{ 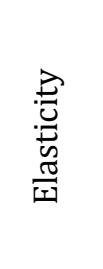 } & L.D & $0.46 \pm 0.02$ & 11.42 & 0.41 & 0.55 & \multirow{4}{*}{$\begin{array}{c}\overline{\mathrm{F}}_{2.46}<\mathrm{F}_{0.05 \%}(3.41) \\
\rightarrow n . s\end{array}$} \\
\hline & Grac. & $0.43 \pm 0.02$ & 10.88 & 0.39 & 0.5 & \\
\hline & I. & $0.46 \pm 0.01$ & 7.28 & 0.44 & 0.51 & \\
\hline & R. Abd. & $0.37 \pm 0.03$ & 17.27 & 0.31 & 0.44 & \\
\hline \multirow{4}{*}{ 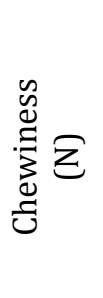 } & L.D & $8.6 \pm 1.5$ & 39.2 & 4.8 & 13.63 & \multirow{4}{*}{$\begin{aligned} \widehat{\mathrm{F}}_{2.14} & <\mathrm{F}_{0.05 \%}(3.41) \\
& \rightarrow n . s\end{aligned}$} \\
\hline & Grac. & $6.62 \pm 1.92$ & 65.04 & 3.14 & 13.82 & \\
\hline & I. & $8.27 \pm 0.74$ & 18.01 & 6.73 & 10.28 & \\
\hline & R. Abd. & $3.09 \pm 1.12$ & 63.00 & 0.89 & 4.59 & \\
\hline
\end{tabular}

\section{CONCLUSION}

The complexity of the description of all parameters of meat texture provided sufficient reasons for the need to identify all environmental factors that have an impact on them.
Improving knowledge about the qualitative aspects of this type of meat could increase consumer appreciation on the horse meat, recent opinions injured by a negative image provided by various illegal slaughter practices existing in worldwide. 
Acknowledgments. This paper was published under the frame of European Social Fund, Human Resources Development Operational Programme 2007-2013, projectno.POSDRU/159/1.5/S/132765.

\section{REFERENCES}

1. Bruna JM, Fernández M, Hierro EM, Ordóñez JA \& Hoz L (2000). Improvement of the sensory properties of dry fermented sausages by the superficial inoculation and/or the addition of intracellular extracts ofMucorracemosus. Journal of Food Science, 65(4), 731-738.

2. Davey CL, Gilbert KV (1974b). Temperature-dependent cooking toughness in beef. Journal of the Science of Food and Agriculture 25(8): 931-938.

3. Franco D, Lorenzo JM (2014). Effect of muscle and intensity of finishing diet on meat quality of foals slaughtered at 15 months. Meat Science 96, 327-334.
4. Lorenzo JM, Sarriés MV, Tateo A, Polidori P, Franco D, Lanza M (2014). Carcass characteristics, meat quality and nutritional value of horsemeat: A review, Meat Science 96, 1478-1488.

5. Szczesniak AS, Brandt MA, Friedman HH (1963). Development of standard rating scales for mechanical parameters of texture and correlation between the objective and the sensory methods of texture evaluation. Journal of Food Science 28(4): 397-403.

6. Szczesniak AS (2002). Texture is a sensory property. Food Quality and Preference 13(4): 215-225.

7. Visessanguan W, Benjakul S, Riebroy S \& Thepkasikul $P$ (2004). Changes in composition and functional properties of proteins and their contributions to Nham characteristics. Meat Science, 66(3), 579 -588.

8. Ward CE, Trent A \& Hildebrand JL (1995). Consumer perceptions of lamb compared with other meats. Sheep and Goat Research Journal, 11, 64-70. 